\title{
Cost-Effective Skyhook Control for Semiactive Vehicle Suspension Applications
}

\author{
Xubin Song*
}

Eaton Corporation, 26201 Northwestern Highway, Southfield, MI 48076, USA

\begin{abstract}
Skyhook control, which is now widely applied to vehicle suspension control, requires two sensors to measure sprung mass acceleration and relative displacement, respectively. In the practical implementation, these two measurement signals are converted into corresponding velocities; then per the skyhook control policy the velocities are employed to decide the desired damping level; finally the damping control signal will be sent to a controllable damper to reduce vibration. For automotive application, the cost as well as reliability is always one of the primary concerns. In this paper, a new scheme is proposed to simplify skyhook control implementation by eliminating one sensor instead of traditionally using two. This design can reduce cost and improve system reliability by reducing the semiactive system complexity. According to a quarter car model, the idea is expatiated on through analysis of the phase relationship between the two velocities that are essential for skyhook control. Then the estimation of the relative velocity from the sprung mass acceleration is formulated. A cost effective skyhook control is derived from using only one accelerometer, and the effectiveness of this new skyhook control approach is demonstrated with ride control through a simulation study of a full car suspension system with application of magneto-rheological (MR) dampers.
\end{abstract}

\section{INTRODUCTION}

The skyhook control was developed in the early 1970s [1] using controllable semiactive dampers. The characteristic of such dampers can be illustrated with Fig. (1). The tunable damping ranges between hard and soft envelopes. With respect to compression and extension, they offer symmetric damping forces. As such, this kind of semiactive damper is referred to as a HH/SS damper. The HH/SS damper can be realized by using a hydraulic, magneto-rheological (MR), or electro-rheological (ER) fluid. High-end automotive markets have seen the rise of applications of semiactive suspensions for better ride and handling performance. Some successful examples are high-performance cars from BMW, MercedesBenz and Toyota, to name a few, which use hydraulic $\mathrm{HH} / \mathrm{SS}$ dampers. Another semiactive suspension in the current market is MagneRide ${ }^{\circledR}$ with application of MR dampers, which is developed by Delphi and Lord Corp. These semiactive suspensions utilize the skyhook controls to achieve the desired vehicle driving performance.

With application of HH/SS dampers, a semiactive quarter-car suspension in Fig. (2) lends itself to interpretation of the skyhook control. It requires two measurement signals of the sprung mass acceleration $\ddot{y}_{1}$ and suspension relative displacement $y_{12}$. These two signals need to be converted into the sprung mass velocity $\dot{y}_{1}$ and the relative velocity $\dot{y}_{12}$ by using properly designed filters, respectively. Then the two-sensor based skyhook control can

*Address correspondence to this author at the Eaton Corporation, 26201 Northwestern Highway, Southfield, MI 48076, USA; E-mail: xubinsong@eaton.com be expressed to produce the damping control signal $C_{\text {skyhook }}$ as the following formula

$$
C_{\text {skyhook }}= \begin{cases}G \dot{y}_{1} & \dot{y}_{1} \dot{y}_{12} \geq 0 \\ 0 & \text { otherwise }\end{cases}
$$

where $G$ is the skyhook control gain.

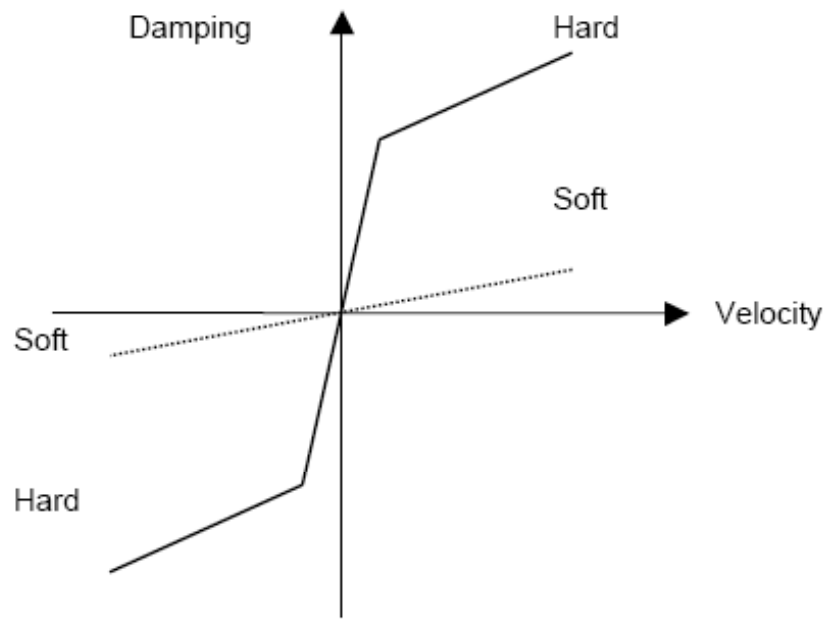

Fig. (1). Damping characteristics of HH/SS Semiactive dampers.

Since the advent of this two-sensor based skyhook control, a significant number of studies have discussed how to improve and effectively implement this damping control [2-9]. However, there has not been much study about the implementation cost, which actually is sensitive and essential for market success in the competitive automotive industry. This report develops a new and easily implemented approach to estimate the relative velocity around the primary resonant frequency region by using the sprung mass acceleration instead of the relative displacement. Thus the proposed 


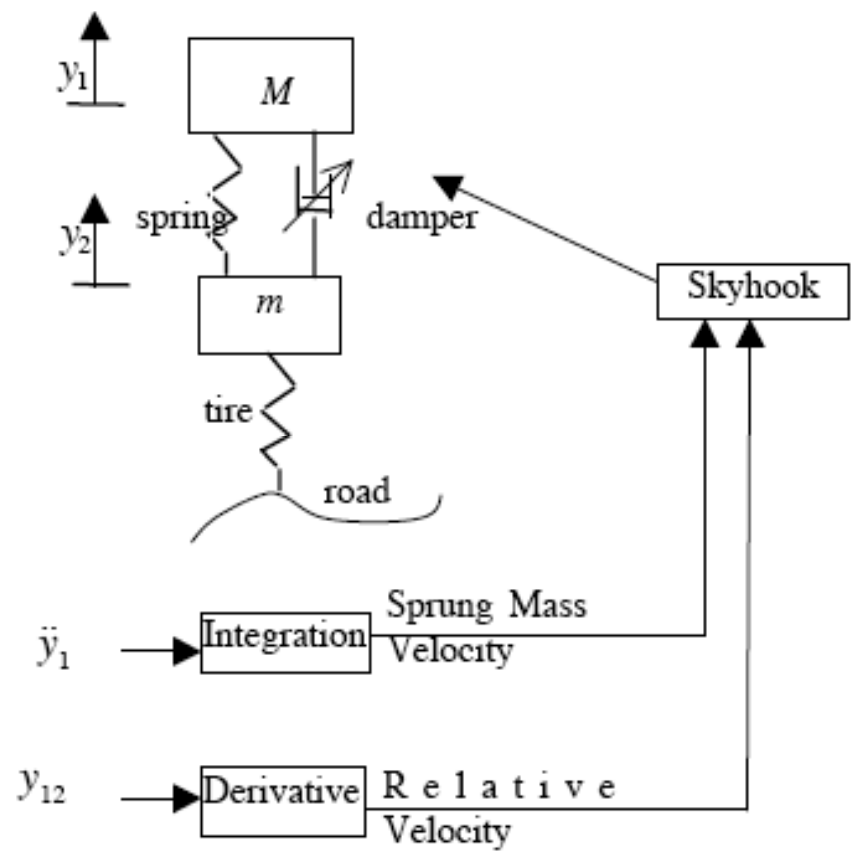

Fig. (2). Two-sensor based Skyhook control.

skyhook control policy can reduce the number of sensors by half and can improve system reliability.

The following sections will elaborate on the development of acceleration sensor based skyhook control. First the phase relationship between velocities will be analyzed. This analysis leads to a new estimation method to obtain the relative velocity from the sprung mass acceleration. Then laid out is a full car model setup with application of MR dampers for simulation study. Next the formulation of skyhook controls for a full car suspension system is elucidated. Finally simulation results are used to demonstrate the effectiveness of this new cost-effective skyhook control.

\section{PHASE RELATIONSHIP BETWEEN VELOCITIES}

The skyhook control in Eq. (1) says that the damping level needs to be changed immediately as soon as the two velocities have different signs. When both velocities have the same sign, the damping required is proportional to the sprung mass velocity. As described above, an accelerometer can be used to derive this velocity. Therefore, one question that can be asked is whether this acceleration signal can be used to estimate the relative velocity. The enlightenment is that skyhook control can create a damping command if the suspension relative velocity direction is known regardless of its magnitude. This inspires the pursuit of the accelerometer based skyhook control instead of using two sensors described in Eq. (1). In this section, the phase relationship between these two velocities is analyzed. Then in the following section a new estimation of relative velocity will be provided to develop a new skyhook control.

According to Fig. (2), the equation of motion for the sprung mass $M$ can be derived as

$$
\begin{aligned}
& M \ddot{y}_{1}+C\left(\dot{y}_{1}-\dot{y}_{2}\right)+K\left(y_{1}-y_{2}\right)=0 \\
& M \ddot{y}_{1}+(C s+K) y_{12}=0
\end{aligned}
$$

where $K$ is the spring stiffness and $C$ represents the damping coefficient of the damper. A proper manipulation of the above two equations leads to the following displacement transmissibility function

$$
\frac{y_{12}}{y_{1}}=\frac{M}{C s+K}\left(-s^{2}\right)
$$

Then the velocity relationship can be expressed as

$$
\frac{\dot{y}_{12}}{\dot{y}_{1}}=\frac{M}{C s+K}\left(-s^{2}\right)
$$

The above equation is used to declare the following phase relationship between these two velocities.

$\angle \dot{y}_{12}-\angle \dot{y}_{1}=\angle \frac{M}{C s+K}$

Eq. (6) clearly shows that the relative velocity lags behind the sprung mass velocity up to 90 degrees. For a semiactive suspension system with unchanged $M$ and $K$, the phase delay depends solely on the damping coefficient $C$. If $C$ is zero, then two velocities are in phase. In general the higher the damping level $C$ the larger the phase-delay. Since $C$ is varying during vibration controls, a feasible solution is to derive an approximate phase relationship between these two velocities. That will be further explained in the following section.

\section{ONE-SENSOR BASED SKYHOOK CONTROL POLICY}

As discussed above, the traditional skyhook control needs two sensors with application of HH/SS dampers. Now one-senor approach will be developed here. If the sprung mass acceleration is measured, then integration of this acceleration can deliver the sprung mass velocity (i.e., the absolute velocity) as following: 


$$
\dot{y}=\frac{1}{s} \ddot{y}_{1}
$$

However, for practical implementation, it is strongly recommended to include a washout filter to remove accelerometer DC component to improve accuracy. Eq. (6) states that the relative velocity lags behind the sprung mass velocity between 0 and 90 degrees. Therefore, the formulation of a first order filter as Eq. (8) is proposed to estimate the relative velocity $\dot{x}$ around the primary resonant frequency

$$
\dot{x}=\frac{\beta}{s+\alpha}\left(\frac{1}{s} \ddot{y}_{1}\right)
$$

where $\alpha$ and $\beta$ are pre-determined constant values.

As such, this approach requires firstly specifying the range of the sprung mass $M$, minimum mass $m_{\min }$ and maximum one $m_{\max }$. Usually we know the suspension stiffness $K$. Furthermore we need to know a priori damper characteristics such as minimum and maximum damping coefficients, $C_{\min }$ and $C_{\max }$. Then $\alpha$ and $\beta$ are recommended to be decided as follows:

$$
\begin{aligned}
& \alpha=K / C_{\text {mean }} \\
& \beta=\left(m_{\text {min }}+m_{\max }\right) / C_{\text {mean }} \\
& C_{\text {mean }}=\left(C_{\text {min }}+C_{\text {max }}\right) / 2
\end{aligned}
$$

Based on the estimated velocity signals from Eqs. (7) and (8), the one-sensor based skyhook control policy can be expressed (similar to no-jerk skyhook [5]) as:

$$
C_{\text {skyhook }}=G \dot{x} \dot{y}(\dot{x} \dot{y}>=0)
$$

where $(\dot{x} \dot{y}>=0)$ is a binary logic function, either one or zero, and $G$ is the skyhook control gain.

One advantage of Eq. (8) is that in the estimate of the relative velocity the high frequency components are significantly reduced because of dropping out $s^{2}$ in comparison to Eq. (5). This reduction implicitly means to automatically attenuate the high frequency components in the skyhook damping control signal. This kind of high frequency attenuation in the control signal is truly desirable for suspension control, because the vehicle suspension needs to have low transmissibility for high frequency vibrations.

\section{SIMULATION MODEL SETUP}

In order to show its effectiveness, a full-car suspension system with application of MR dampers will be set up for this study. In this section, the models of MR damper and the vehicle suspension system are briefly introduced.

\section{MR Damper Model}

The MR damper configuration is shown in Fig. (3). Magneto-rheological fluids exhibit rheological properties that are controllable by a tunable magnetic field around coils. This property is used in MR dampers to provide different damping forces dependent on the strength of the magnetic field that is created within the damper. The magnetic field is controlled by the electrical current supplied to the coils of the MR valve, which is commonly used to restrict the fluid flow as the damper piston moves relative to the damper body. MR damper force is continuously tunable between maximum $\mathrm{HH}$ and minimum SS damping level. The higher the current to the MR damper the larger the damping force as illustrated in Fig. (4).

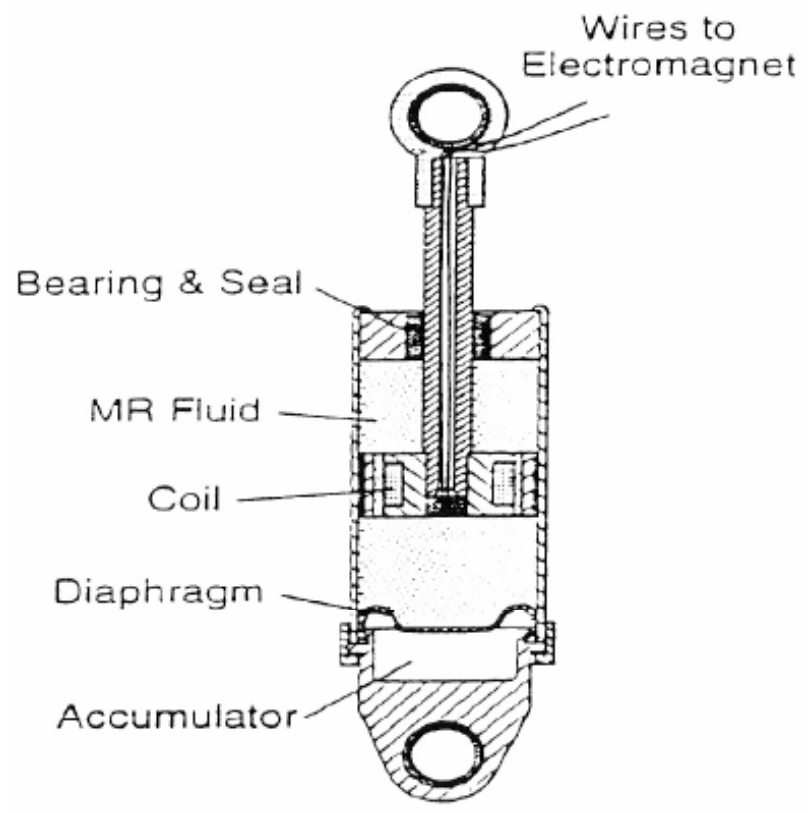

Fig. (3). Magneto-Rheological (MR) damper (In courtesy of Lord corporation).

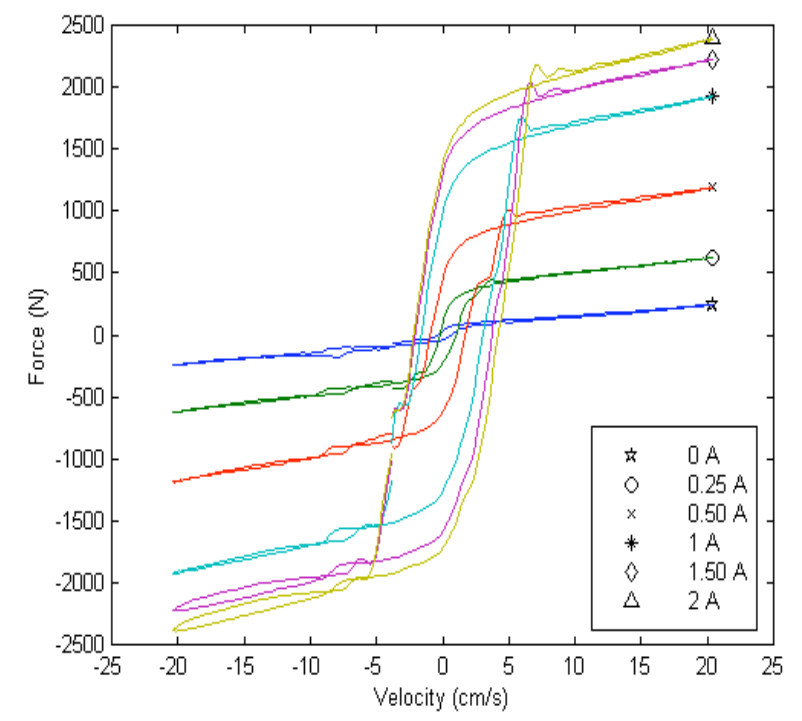

Fig. (4). MR Damper experimental data.

There are several ways to model the MR dampers [1012], for example, the Bouc-Wen and Preisach hysteresis model. For this study the nonparametric modeling approach is adopted [10]. This MR damper model is composed of the following three functions:

1) An amplitude function

$A_{m r}(I)=\sum_{i=0}^{n} a_{i} I^{i}$ 

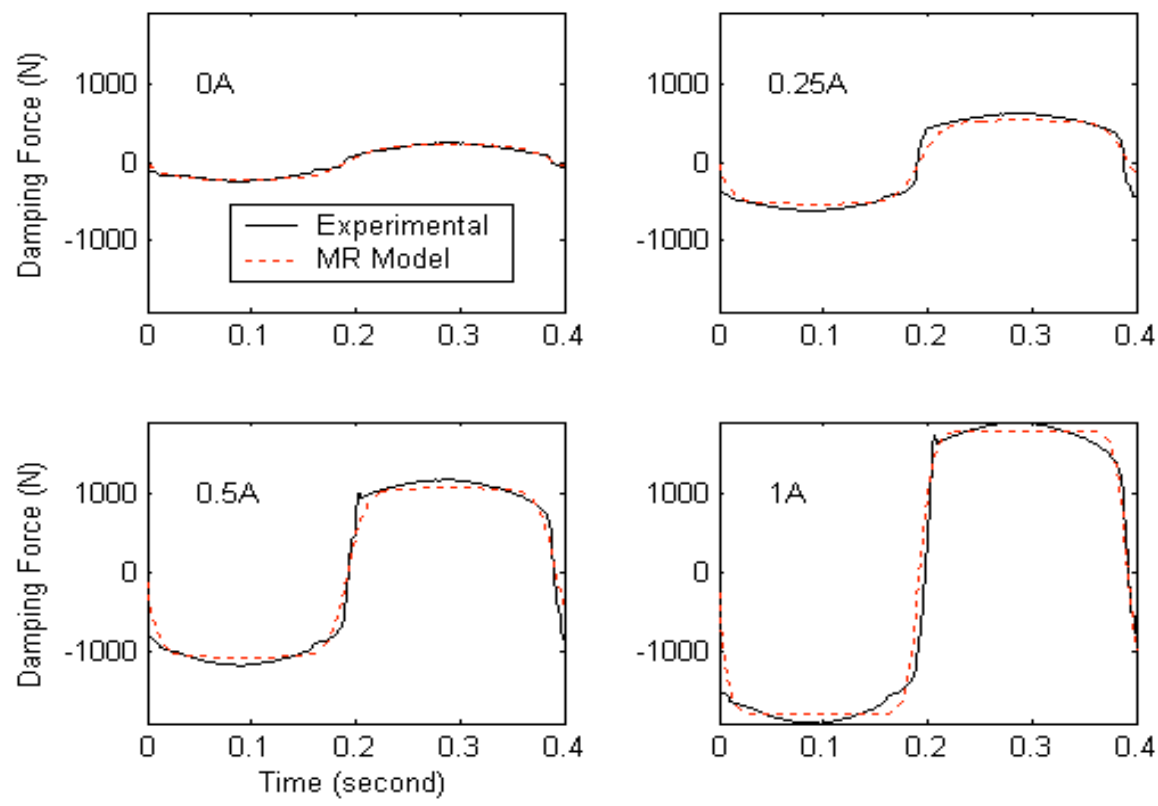

(a) Time Domain
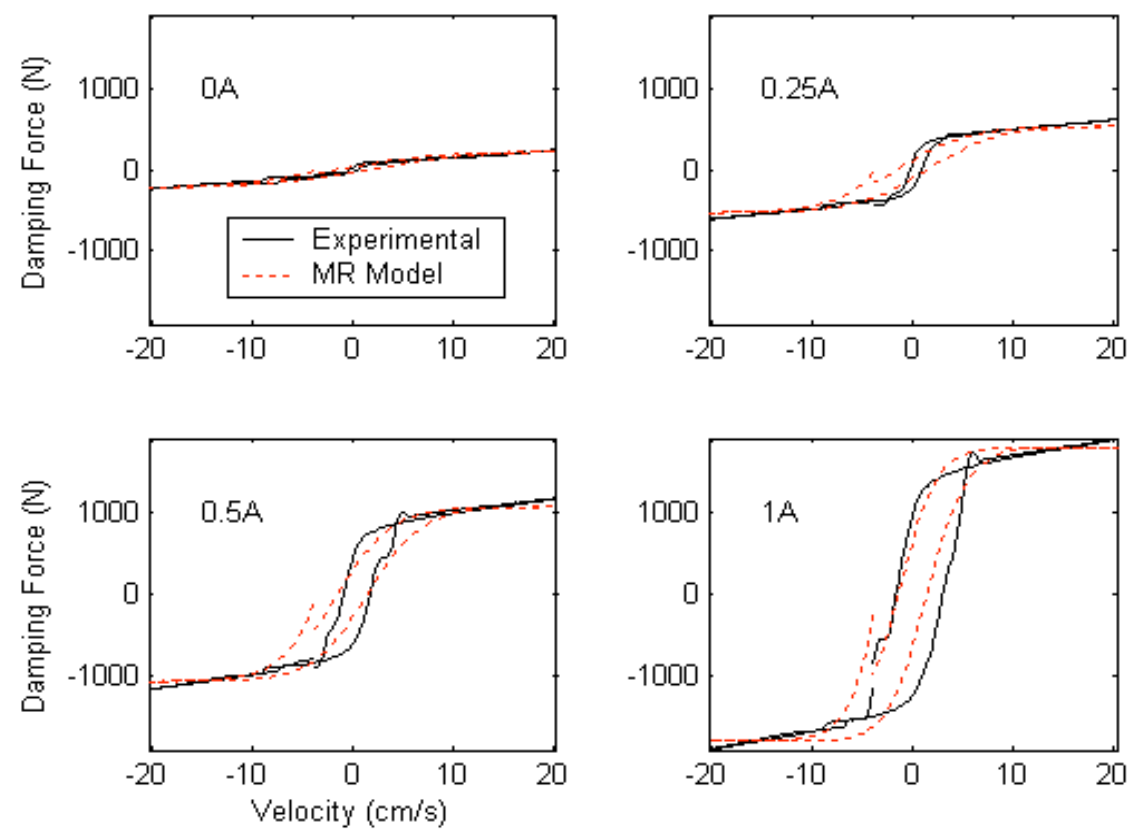

(b) Force vs. Velocity

Fig. (5). MR Damper model validation: (a) Time domain; (b) Force vs. Velocity.

2) A backbone-shape function

$S_{b}(I, V)=\tanh \left[\left(b_{1} I+b_{2}\right) V\right]$

$F_{s}=A_{m r}(I) S_{b}(I, V)$

3) A delay function (used to create the hysteresis)

$\left\{\begin{array}{l}\dot{x}=-A x+B F_{s} \\ F_{h}=A x+C F_{s}\end{array}\right.$
Fig. (5) shows that the composition of these three equations can well represent this MR damper. In the model, $A=186.5, B=1, C=0$, and the other parameters are shown in Fig. (6). Furthermore, it is worth noting that Eq. (13) is an expanded first-order filter that is used to mimic the hysteresis loops of the damper, while Eq. (12) captures the bilinear behavior of the MR damper.

\section{Full Car Model Setup}

Skyhook control has been studied to improve vehicle ride comfort in the automotive industry for decades. For this 


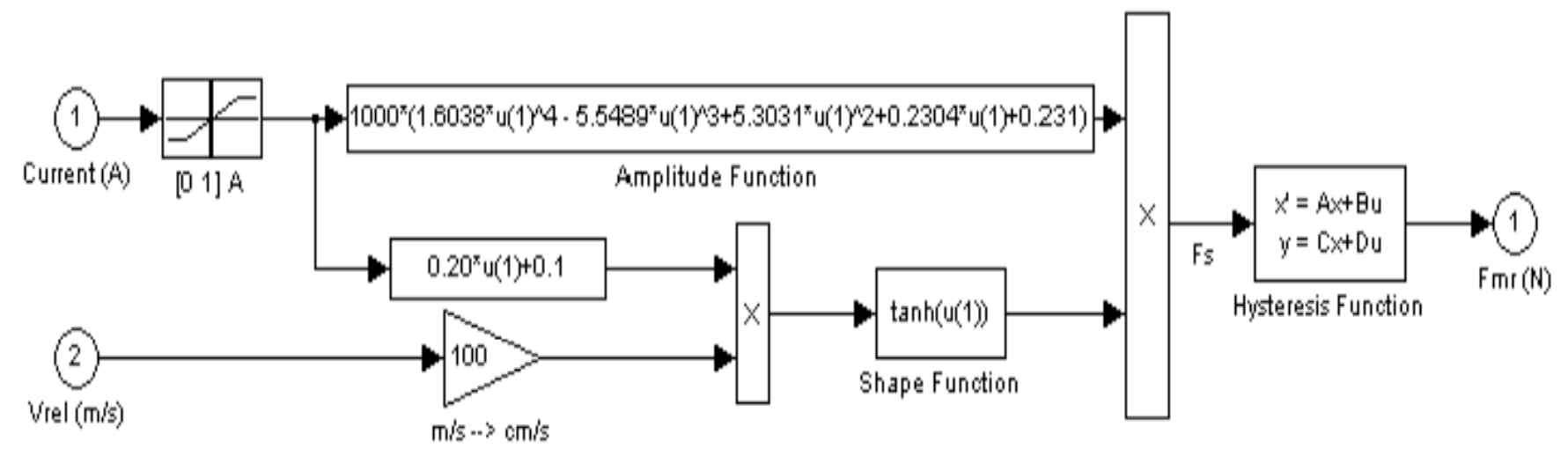

Fig. (6). Non-parametric MR damper model in Simulink.

study, a full car model in Fig. (7) is built to test the effectiveness of the skyhook controls. It has 7 degrees-offreedom (DOFs): four relative motions in correspondence to four suspension corners, and three vehicle body DOFs of bounce, pitch and roll. The four independent suspensions consist of springs and MR dampers. Bounce, pitch and roll accelerations are used to evaluate the vehicle ride control and comfort.

The suspension-related parameters are presented in Table 1, which specifies the rocker arm ratio, spring rate, unsprung mass, and tire stiffness and damping for each corner, respectively. The inertia parameters for this simulated vehicle are:

Vehicle Sprung Mass $=1720 \mathrm{Kg}$

Inertia at Longitudinal Axis $=475 \mathrm{Kg}-\mathrm{m}^{2}$

Inertia at Lateral Axis $=2730 \mathrm{Kg}-\mathrm{m}^{2}$
Table 1. Suspension Related Vehicle Parameters

\begin{tabular}{|c|c|c|c|c|}
\hline & $\begin{array}{c}\text { Front } \\
\text { Left }\end{array}$ & $\begin{array}{c}\text { Front } \\
\text { Right }\end{array}$ & $\begin{array}{c}\text { Rear } \\
\text { Right }\end{array}$ & $\begin{array}{c}\text { Rear } \\
\text { Left }\end{array}$ \\
\hline \hline Rocker Arm Ratio & 0.75 & 0.75 & 0.75 & 0.75 \\
\hline Spring Rate (KN/m) & 33.8 & 33.0 & 34.0 & 34.7 \\
\hline $\begin{array}{c}\text { Unsprung Mass } \\
(\text { Kg) }\end{array}$ & 45 & 45 & 40 & 40 \\
\hline $\begin{array}{c}\text { Tire Stiffness } \\
(\mathrm{KN} / \mathrm{m})\end{array}$ & 300 & 300 & 300 & 300 \\
\hline $\begin{array}{c}\text { Tire Damping } \\
(\mathrm{N} /(\mathrm{m} / \mathrm{s}))\end{array}$ & 50 & 50 & 50 & 50 \\
\hline
\end{tabular}

According to the above vehicle setup, the natural frequencies can be approximately estimated by linearizing

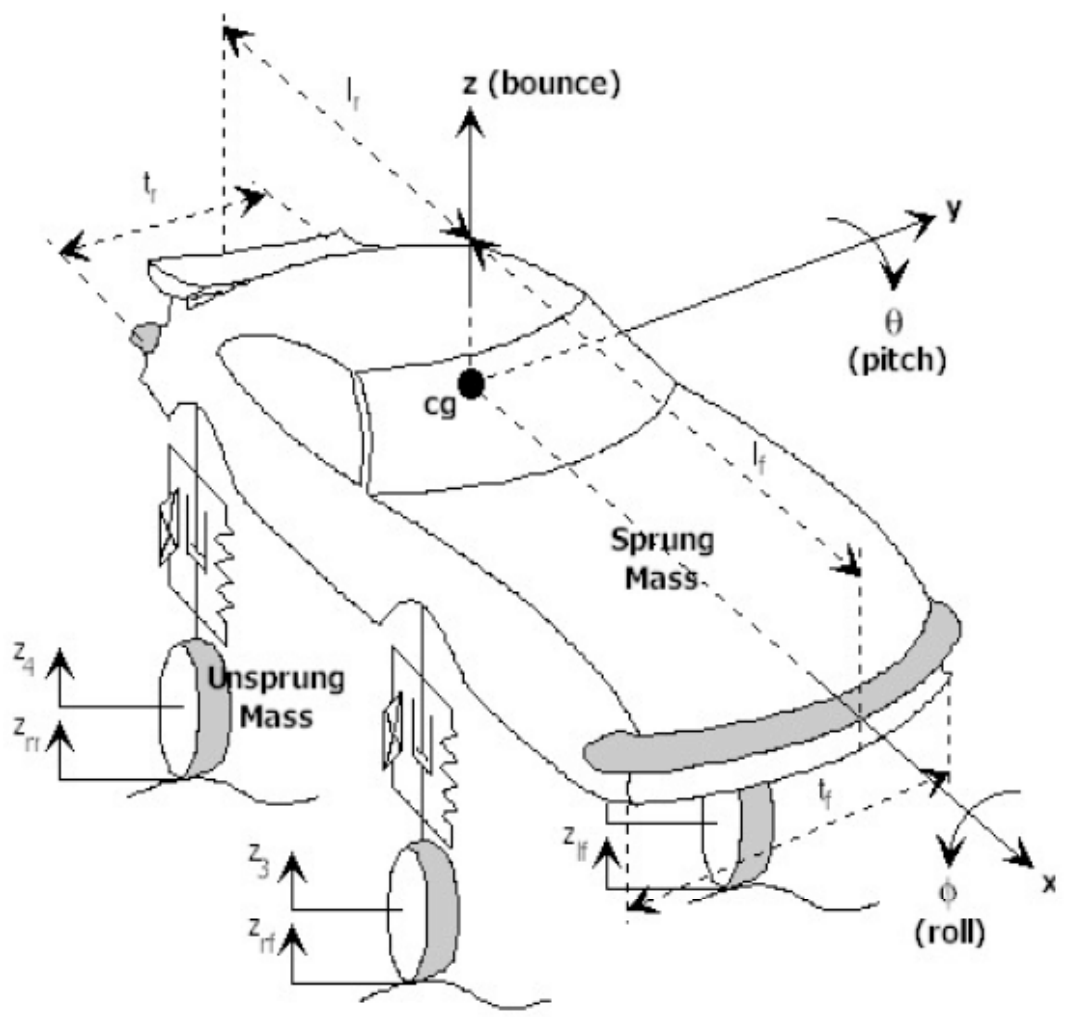

Fig. (7). Full car model with respect to inertial coordinate. 

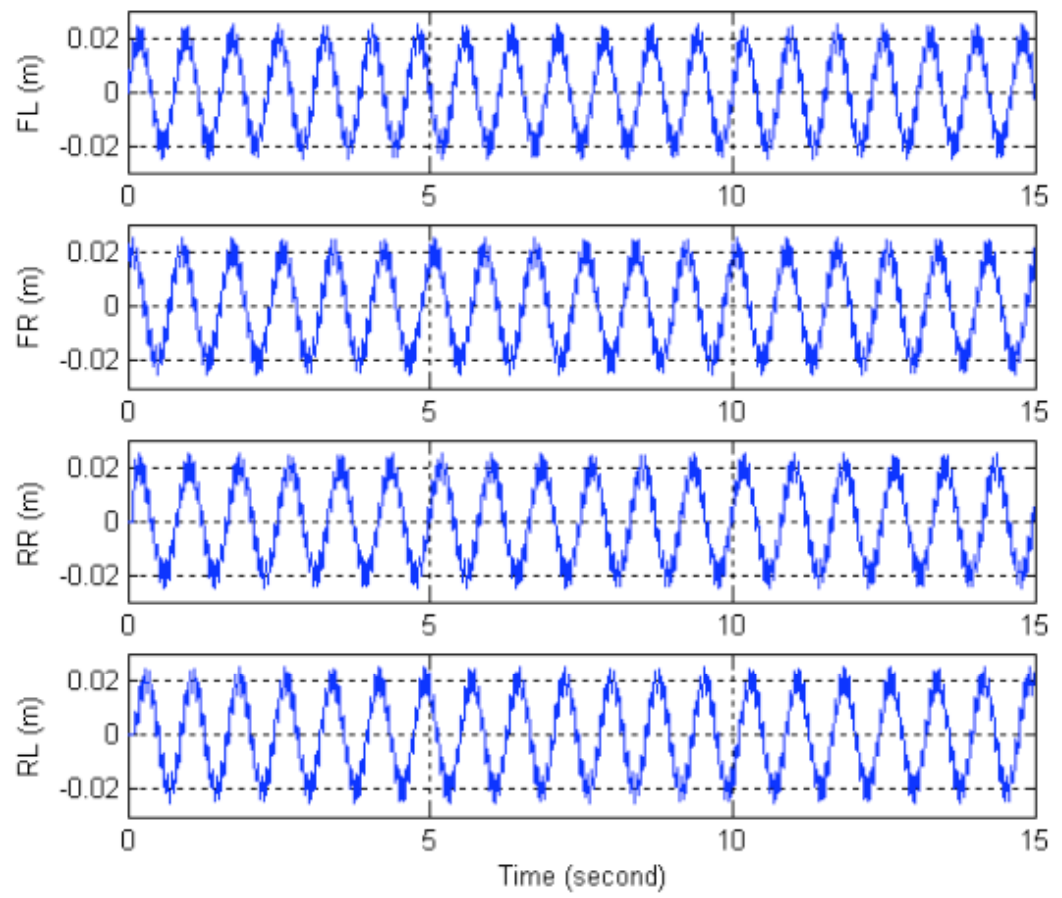

Fig. (8). Excitations on four wheels for simulation study.

the full car model. The suspension system has two bounce modes of 1.26 and $13.30 \mathrm{~Hz}$, two pitch modes of 1.45 and $14.10 \mathrm{~Hz}$, and two roll natural frequencies of 2.10 and 13.30 Hz. So in order to test the effectiveness of studied skyhook controls, the road excitation is designed to have a mixture of 1.30 and $13.50 \mathrm{~Hz}$, as shown in Fig. (8). As such, each suspension corner can be exposed to an appropriate vibration excitation for this simulation study.

\section{SKYHOOK CONTROL SETUP}

Compared to a semiactive quarter car in Fig. (2), application of skyhooks to a full car suspension system is more complicated. The vehicle rigid body (i.e., the sprung mass) has three DOFs of bounce, pitch and roll, which are abbreviated as BPR in the rest of the paper. As shown in Fig. (7), the bounce acceleration along the vertical direction has units of $\mathrm{m} / \mathrm{s}^{2}$, while both roll and pitch accelerations are rotational signals in $\mathrm{rad} / \mathrm{s}^{2}$. Four suspension corners are labeled as LF (left front), RF (right front), LR (left rear), and RR (right rear), respectively. The following section goes into implementation details.

\section{Two-Sensor Based Skyhook}

The traditional skyhook control for a full car suspension system can be realized by using three BPR velocities together with four suspension relative velocities, as shown in Fig. (9). That means the suspension control system needs to use seven sensors. Similar to the quarter-car system, three BPR accelerations can be measured and then used to obtain the BPR velocities $\dot{y}_{1}^{i}(i=B, P, R)$ of the vehicle body per Eq. (7). The relative velocities at each suspension corner

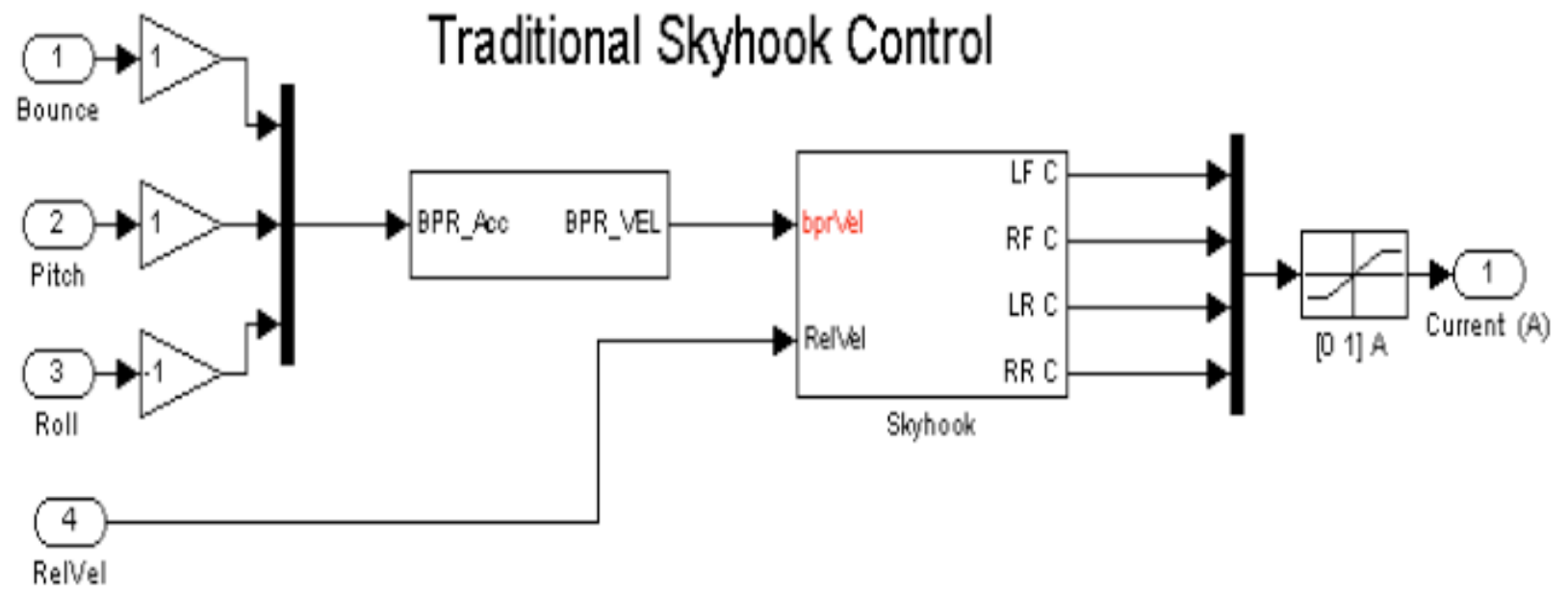

Fig. (9). Traditional two-sensor based skyhook control application in Simulink. 
$\dot{y}_{12}^{j}(j=L F, R F, L R, R R)$ are derived from the measured relative suspension displacements. Each of the BPR velocities creates a damping command for each damper with the corresponding relative velocity, as further explained in Eq. (14a).

$C_{j}^{i}= \begin{cases}G_{j}^{i} \dot{y}_{1}^{i} & \dot{y}_{1}^{i} \dot{y}_{12}^{j} \geq 0 \\ 0 & \text { otherwise }\end{cases}$

where $i=B, P$, and $R$, and $j=L F, R F, L R$, and $R R$.

Then the dampers can have the following damping control commands

$$
\begin{aligned}
& C_{L F}=C_{L F}^{B}+C_{L F}^{P}+C_{L F}^{R} \\
& C_{R F}=C_{R F}^{B}+C_{R F}^{P}-C_{R F}^{R} \\
& C_{L R}=C_{L R}^{B}-C_{L R}^{P}+C_{L R}^{R} \\
& C_{R R}=C_{R R}^{B}-C_{R R}^{P}-C_{R R}^{R}
\end{aligned}
$$

\section{One-Sensor Based Skyhook}

This section will explain the application of the newly proposed skyhook control of Eqs. (7-10) to the full car suspension control system. Like the two-sensor based skyhook, three inertia sensors at the gravity center of the vehicle body are used to measure BPR accelerations, respectively. Similarly, the accelerations are used to calculate the BPR velocities of the vehicle body, $\dot{y}^{i}(i=B, P, R)$. But for this one-sensor based control, these three accelerations are also used to estimate three relative velocities $\dot{x}^{i}(i=B, P, R)$. The two parameters of $\alpha$ and $\beta$ of Eq. (8) for BPR relative velocities are defined in Table 2 for this simulation study. Then these velocity signals are used to produce the BPR damping commands as:

$C^{i}=G^{i} \dot{x}^{i} \dot{y}^{i}\left(\dot{x}^{i} \dot{y}^{i}>=0\right)$

where $i=B, P$, and $R$. Next $C^{i}$ is properly split to each damper empirically as well as per vehicle chassis design. Finally, the damper commands can be formulated as following:

$$
\begin{aligned}
& C_{L F}=\mu^{B} C^{B}+\mu^{P} C^{P}+\mu^{R} C^{R} \\
& C_{R F}=\mu^{B} C^{B}+\mu^{P} C_{R F}^{P}-\left(1-\mu^{R}\right) C_{R F}^{R} \\
& C_{L R}=\left(1-\mu^{B}\right) C_{L R}^{B}-\left(1-\mu^{P}\right) C_{L R}^{P}+\mu^{R} C_{L R}^{R} \\
& C_{R R}=\left(1-\mu^{B}\right) C_{R R}^{B}-\left(1-\mu^{P}\right) C_{R R}^{P}-\left(1-\mu^{R}\right) C_{R R}^{R}
\end{aligned}
$$

Table 2. Relative Velocity Filter Setup for One-Sensor Based Skyhook Control

\begin{tabular}{|c|c|c|c|}
\hline & Bounce Estimator & Pitch Estimator & Roll Estimator \\
\hline \hline$\alpha$ & 4 & 5 & 6 \\
\hline$\beta$ & 3.8 & 4.8 & 5.8 \\
\hline
\end{tabular}

Fig. (10) shows the cost-effective implementation diagram in Simulink using the one-sensor based skyhook control strategy. This suspension control system requires only three inertia sensors.

\section{SIMULATION RESULTS}

The simulation focuses on vehicle ride comfort, representative of the vehicle body accelerations. For comparison purpose, a passive suspension is also simulated with application of $0.5 \mathrm{~A}$ to the two front MR dampers and 0.35A for rear dampers, respectively. The passive suspension is treated as a baseline for skyhook controls.

The BPR accelerations from all three simulation cases are presented from Figs. (11-13) in the frequency domain. The legend 'Skyhook' represents the two-sensor based strategy, while 'Cost Effective Skyhook' stands for the onesensor based strategy.

From Fig. (11), it can be observed that the bounce vibration around both primary and secondary suspension frequencies is significantly reduced with both skyhook strategies in comparison to the passive suspension. Figs. (12 and 13) show the pitch and roll accelerations, respectively. Both controls can lower the peaks at the secondary suspension frequency. One subtle observation is that the onesensor based control provides better control of the primary pitch peak. That may be induced by smaller relative velocity estimation in the high frequency range from Eq. (8). Overall, the cost effective skyhook control provides competitive

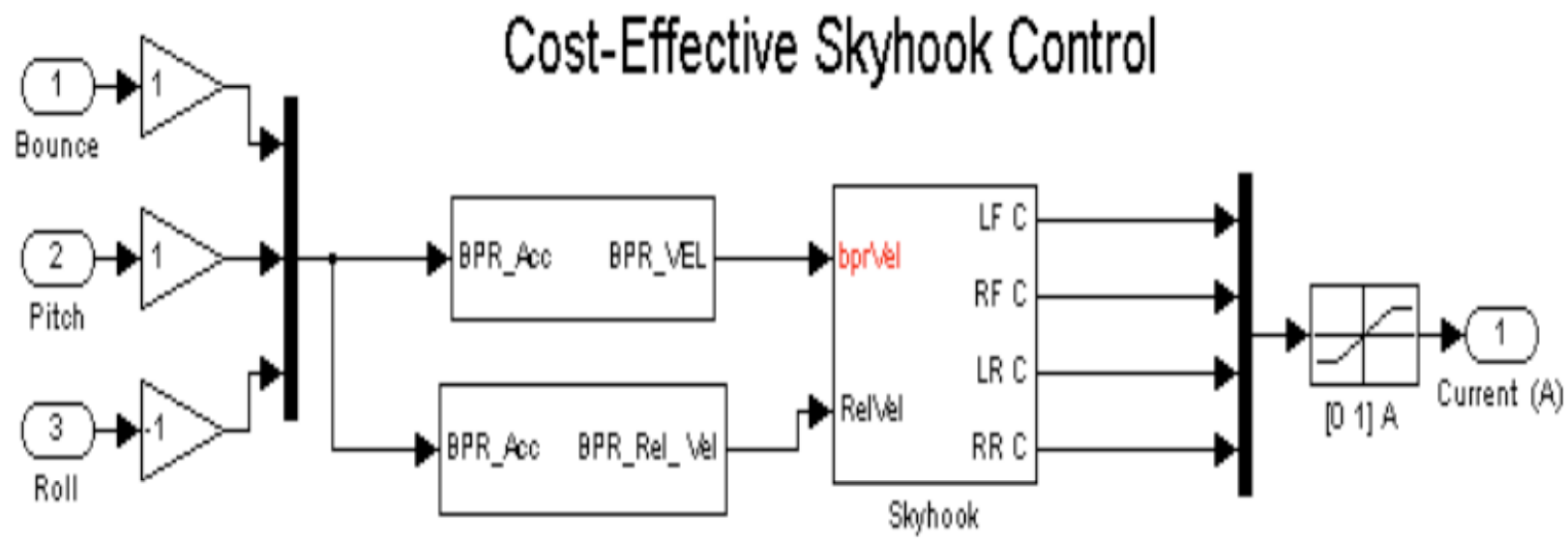

Fig. (10). Cost-effective implementation of one-sensor based skyhook control in Simulink. 


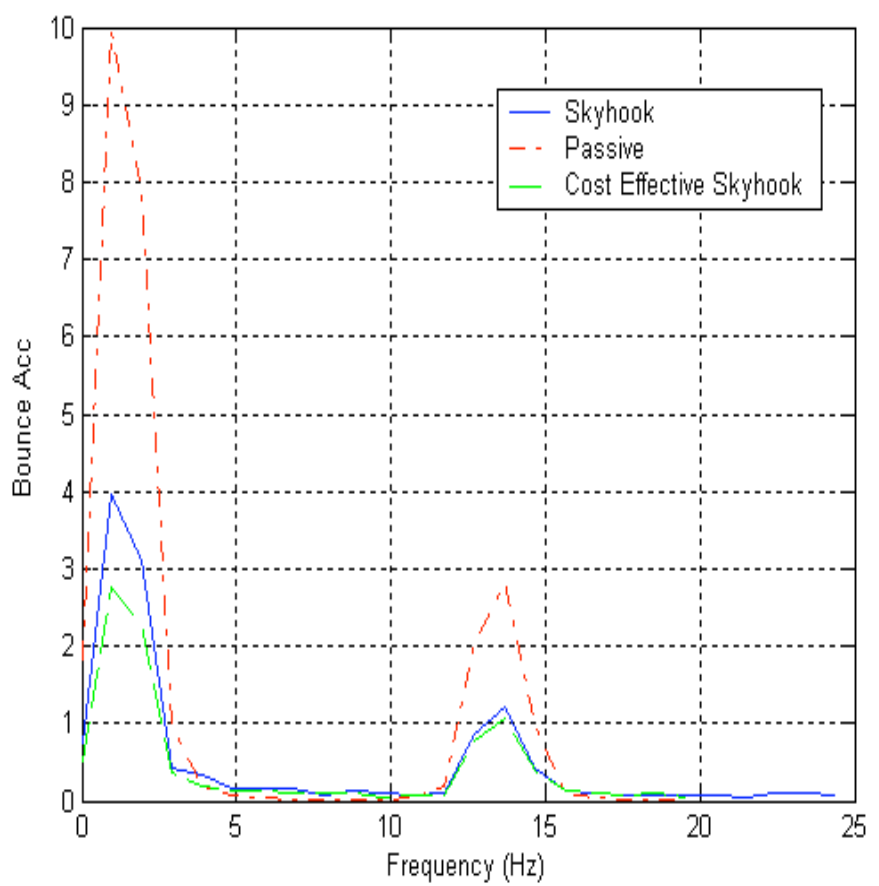

Fig. (11). Comparisons of Bounce acceleration.

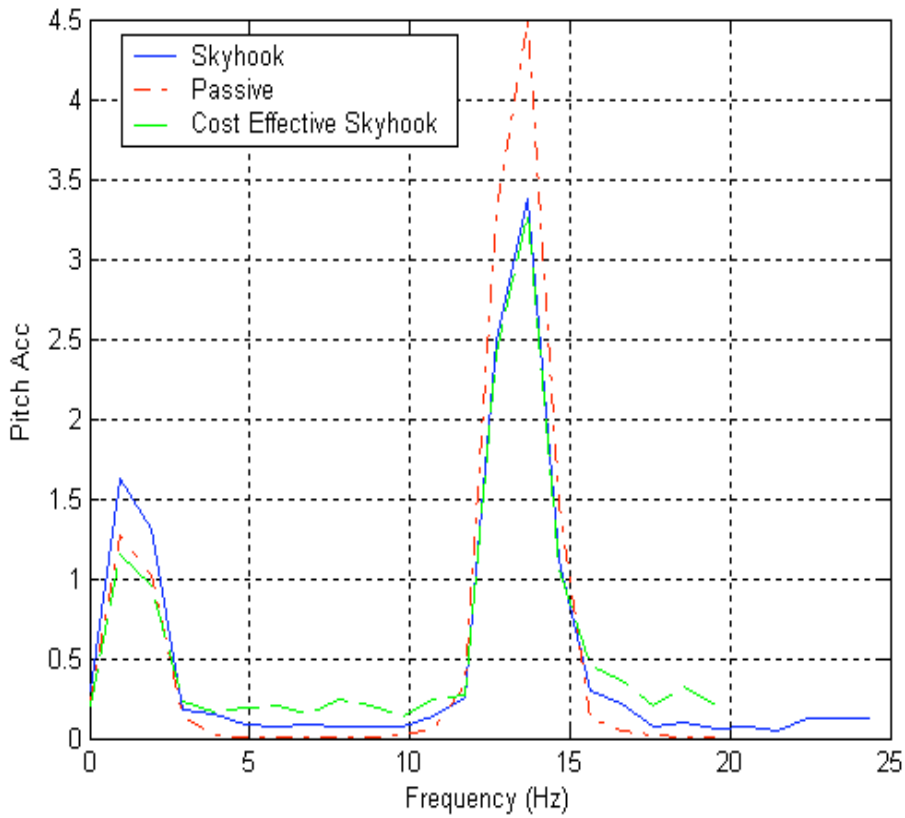

Fig. (12). Comparisons of Pitch acceleration.

performance against the traditional skyhook control. Thus, the one-sensor based skyhook control provides another new avenue to simplify semiactive vehicle suspension implementation.

\section{CONCLUSIONS}

The traditional two-sensor based skyhook control is briefed first. Then using a quarter-car suspension configuration the phase relationship between sprung mass and relative velocity is analyzed. From this phase analysis, a new one-sensor based skyhook control strategy is developed for this study.

A full car suspension system model is then used to demonstrate the effectiveness of the one-sensor based skyhook control compared to the traditional skyhook control as well as the passive suspension. The simulation results show that the proposed skyhook with three sensors can achieve competitive ride comfort performance in comparison 


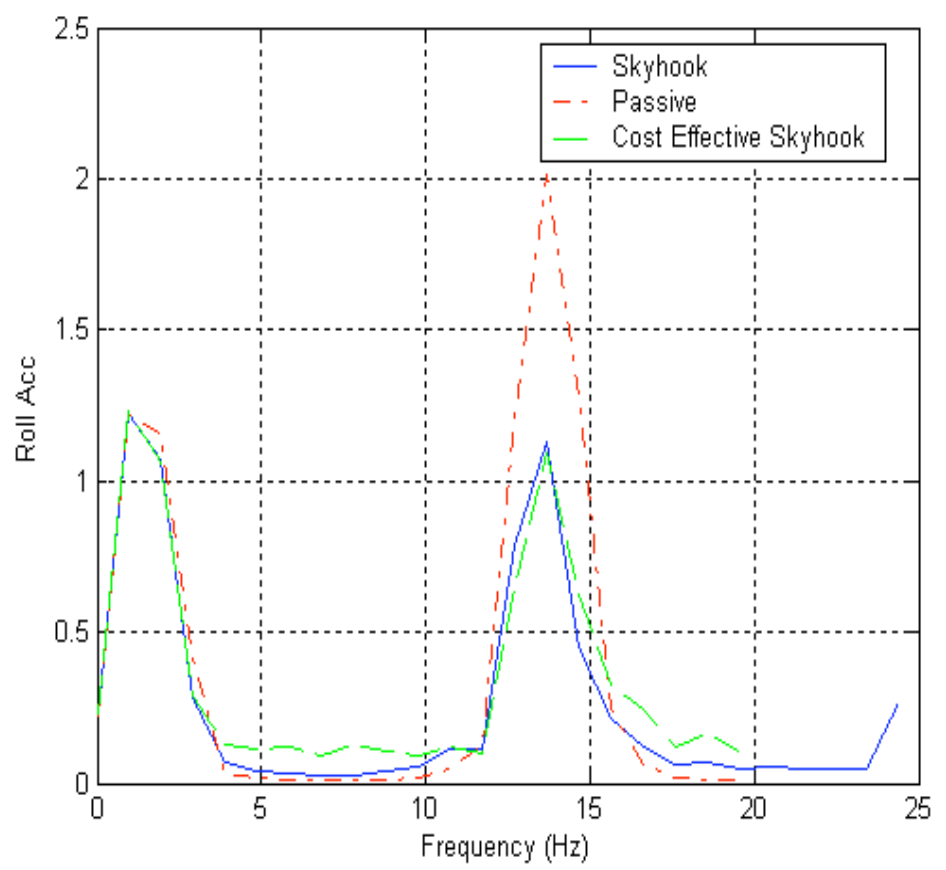

Fig. (13). Comparisons of Roll acceleration.

to the seven-sensor based traditional skyhook. However, more studies need to be done to further investigate the application of this simplified one-sensor based skyhook control with other suspension-related vehicle performances.

For the automobile industry, both cost and reliability are always a big concern. This will also challenge the control engineers to develop more cost-effective control algorithms for reducing system complexity and cost but maintain a high-quality bar for productions. This study highlights one example of such engineering efforts that can lead to that goal.

\section{ACKNOWLEDGEMENT}

The author uses the MR damper data from Lord Corporation. His working experience at Visteon Corp motivates him to continue to explore the vehicle semiactive suspension development, even though he is now working at Eaton Corp and focusing on powertrain controls for commercial vehicles.

\section{REFERENCES}

[1] D.C. Karnopp, and M.J. Crospy, "System for Controlling the Transmission of Energy between Spaced Members", U.S. Patent 3,807,678, April 1974.

[2] D. E. Ivers and L. R. Miller, "Semiactive suspension technology: an evolutionary view", ASME Advanced Automotive Technologies, DE-40, Book No. H00719-1991, pp. 327-346, 1991.

[3] X. Song, "Design of adaptive vibration control systems with application to magneto-rheological dampers", Doctor of Philosophy
Dissertation, Virginia Polytechnic Institute and State University, Blacksburg, Virginia, 1999.

[4] M. Bieber, S. M. Mackool, and D. S. Rhode, "Vehicle Suspension Control Systems", Patent No. 5,864,768, Jan. 26, 1999.

[5] M. Ahmadian, X. Song, and S.C. Southward, "No-jerk skyhook control methods for semiactive suspensions", ASME Journal of Vibration and Acoustics, Vol. 126, No. 4, pp. 580-584, October 2004.

[6] S. B. Choi, J. H. Choi, Y. S. Lee, and M. S. Han, "Vibration control of an ER seat suspension for a commercial vehicle", Journal of Dynamic Systems, Measurement, and Control, ASME, Vol. 125, pp. 60-68, March 2003.

[7] Y. T. Choi, and N. M. Wereley, "Biodynamic response mitigation to shock loads using magnetorheological helicopter crew seat suspension", Journal of Aircraft, Vol. 42, No. 5, pp. 1288-1295, September-October 2005.

[8] Y. Liu, T. P. Waters and M. J. Brennan, "A comparison of semiactive damping control strategies for vibration isolation of harmonic disturbances", Journal of Sound and Vibrations, Vol. 280, pp. 2139.

[9] K. S. Hong, H. C. Sohn and J. K. Hedrick, "Modified skyhook control of semi-active suspensions: a new model, gain scheduling, and hardware-in-the-loop tuning," Journal of Dynamic Systems, Measurement and Control, ASME, Vol. 124, pp. 158-167, March 2002

[10] M. Ahmadian, and X. Song, "Non-parametric model of magnetorheological dampers", Proceedings of $17^{\text {th }}$ Biennial Conference on Mechanical Vibration and Noise, ASME DETC, September 12-14, Las Vegas, NV, 1999.

[11] B. F. Spencer, S. J.Dyke, M. K. Sain, and J. D. Carlson, "Phenomenological model of a magnetorheological damper," ASCE Journal of Engineering Mechanics, 1996.

[12] R. B. Gobert, K. A. Morris and D. W. L. Wang, "Passivity-based stability and control of hysteresis in smart actuators," IEEE Transactions on Control Systems Technology, Vol. 9, No. 1, pp. 516, January 2001.

(C) Xubin Song; Licensee Bentham Open.

This is an open access article licensed under the terms of the Creative Commons Attribution Non-Commercial License (http://creativecommons.org/licenses/by$\mathrm{nc} / 3.0 /$ ), which permits unrestricted, non-commercial use, distribution and reproduction in any medium, provided the work is properly cited. 